\title{
Outdoor Vector Biting, Feeding on Animal and Pyrethroid Resistance Potential Drivers of Persistent Malaria Transmission in Zanzibar
}

Revocatus Musyangi Musiba ( $\sim$ rmusiba@ihi.or.tz)

Ifakara Health Institute https://orcid.org/0000-0002-6697-9931

Brian B. Tarimo

Ifakara Health Institute

April Monroe

Johns Hopkins University Center for Communication Programs

Dickson Msaky

Ifakara Health Institute

Halfan Ngowo

Ifakara Health Institute

Kimberly Mihayo

Ifakara Health Institute

Alex Limwagu

Ifakara Health Institute

Godlove T. Chila

Ifakara Health Institute

Gasper K. Shubis

Ifakara Health Institute

Ahmada Ibrahim

Tanzania Bureau of Standards

George Greer

US Agency for International Development: USAID

Juma H. Mcha

Zanzibar Ministry of Health

Faiza Abbas

Zanzibar Ministry of Health

Abdullah Ali

Zanzibar Ministry of Health

Fredros 0 Okumu

Ifakara Health Institute

Samson Kiware 


\section{Research Article}

Keywords: Entomological drivers, residual transmission, novel tools, pyrethroids, Insecticide resistance

Posted Date: January 24th, 2022

DOI: https://doi.org/10.21203/rs.3.rs-1181548/v1

License: (c) (1) This work is licensed under a Creative Commons Attribution 4.0 International License. Read Full License 


\section{Abstract}

\section{Background:}

Low-level of malaria transmission persist in Zanzibar despite high coverage of core vector control interventions. This study was carried out in hot-spot shehias to better understand entomological factors that may contribute to residual malaria transmission in Zanzibar.

\section{Methods:}

A total of 135 households were randomly selected from six sites and consented to participate with 20-25 households per site. Mosquito vector surveillance was carried out indoors and outdoors from 6:00PM7:00AM using miniaturized double net trap (DN-Mini ${ }^{\mathrm{TM}}$ ). Additional collections were done indoors using mouth aspirators to retrieve resting mosquitoes from wall and ceiling surfaces, and outdoors using resting bucket and pit traps. All collected mosquitoes were morphologically and genetically (PCR) analysed in the laboratory. All collected anopheline and blood-fed mosquitoes were analysed for sporozoite infection and blood meal host preferences by Circumsporozoite Protein ELISA and blood meal ELISA respectively. The differences between indoor and outdoor mosquito biting rates were analysed using generalized linear mixed models. Levels of resistance to commonly used insecticides were quantified by WHO susceptibility tests.

\section{Results:}

Out of 704 malaria vectors collected across 135 households, PCR analysis shows that $98.60 \%$ were Anopheles arabiensis, $0.6 \%$ Anopheles merus and 0.6\% Anopheles gambiae.s.s. Sporozoite ELISA analysis indicates that all mosquitoes were negative for the malaria parasite. The results show that more An. arabiensis were collected outdoor ( 85\%) compared to indoor ( 15\%). Furthermore, large numbers of An. arabiensis were caught in outdoor resting sites, where the pit trap $(67.2 \%)$ collected more mosquitoes compared to the outdoor DN-Mini trap (32.8\%). Nearly two-thirds (60.7\%) of blood-fed mosquitoes had obtained blood meals from non-human hosts. Mosquitoes displayed non-uniform susceptibility status and resistance intensity among the tested insecticides across the study sites to all WHO recommended insecticides across the study sites.

\section{Conclusion:}

This study suggests that in contexts such as Zanzibar, testing of novel techniques to complement indoor protection and targeting outdoor biting and/or resting mosquitoes, may be warranted to complement existing interventions and contribute to malaria elimination efforts. The study highlights the need to implement novel interventions and/or adaptations of strategies that can target outdoors biting mosquitoes.

\section{Introduction}


Current vector control interventions, notably long-lasting insecticide treated nets (LLINs) and indoor residual spraying (IRS), have contributed to significant reductions in malaria burden[1-4]. The archipelago of Zanzibar, which is part of the United Republic of Tanzania, located on the coast of East Africa, has experienced a considerable reduction in malaria burden. Reduction in parasite prevalence has been observed from historical levels of $75 \%$ to $<1.5 \%$ by 2009 [5], with a further reduction to $<0.1 \%$ by 2016 [6]. This decline in Malaria cases is attributed to wide and sustained use of malaria control measures such as indoor residual spraying (IRS) of households, long lasting insecticide treated bed nets (LLINs), the use of rapid diagnostic tests (RDTs), and case management with artemisinin-based combination therapy (ACTs) [7]. With such low parasite prevalence rates, Zanzibar can feasibly aim for elimination of the disease[8].

LLINs and IRS effectively reduce malaria transmission by targeting indoor feeding (endophagic) and resting (endophilic) mosquitoes $[9,10]$. These interventions offer robust individual protection from indoor malaria vectors and can confer community protection when high levels of coverage are achieved [11]. The sustained and wide range use of LLINs and IRS has led to changes in the vector population in some contexts due to the development of physiological or behavioral resistance [7]. Physiological resistance involves the capability of the vector to physiologically tolerate the insecticide present in LLINs and IRS leading to a prolonged life span. While behavioral resistance involves behavioral plasticity from endophilic, endophagic, and anthropophilic mosquitoes to more exophilic, exophagic, and zoophilic mosquitoes to escape from contact with insecticides in LLINs and IRS [7]. In both instances, the effectiveness of vector control interventions may be diminished.

Data collected in 2013 and 2014 indicated that the predominant malaria vector species were $A n$. arabiensis (76.0\%) in Pemba and An. gambiae (83.5\%) in Unguja (data collected between June 2013 and February 2014 from three sites in Pemba island and four sites in Unguja)[12]. The FY 2015 PMI Malaria Operational Plan, based on ZAMEP mosquito collections, reported similar findings. However, recent data from routine entomological surveillance conducted in Unguja by ZAMEP show an increase in the numbers of An. arabiensis collected relative to An. gambiae s.s. Furthermore, increasing outdoor biting exposure has been observed in both Pemba and Unguja evidenced from recent human-landing catches done indoors and outdoors (ZAMEP report, unpublished data). This outdoor biting behaviour has been shown to occur early in the evening, peaking as early as 8-10 PM (unpublished data from ZAMEP). In addition to endophagic and exophagic behaviour, Anopheles mosquitoes in Zanzibar have been shown to be resistant to pyrethroid-based insecticides[13][14]. In 2012, there was a policy change in the insecticide used in IRS from pyrethroids to bendiocarbs, which was later abandoned in 2014 due to its short residual life span that led to increased IRS operational costs. Currently, pirimiphos-methyl is the insecticide of choice for IRS in Zanzibar and there has not been any reported resistance against it. Increasing insecticide resistance is a major hurdle for malaria control efforts in sub-Sahara Africa (SSA). Therefore, routine surveillance is essential to ensure early detection of resistance against insecticide(s) used and forms the basis on the choice of insecticide to be used for LLINs and IRS. 
Recent data from Zanzibar show that malaria cases have been mainly focalized in specific areas with high vector abundance and possibly, where people have recently travelled from mainland Tanzania [8]. To better understand potential entomological drivers of persistent low-level malaria transmission in Zanzibar, investigation on vector biting and resting patterns, host preferences, and levels of resistance to commonly used insecticides was carried out. This work was carried out as part of a larger research project investigating both entomological and human behavioral factors that may be contributing to residual malaria transmission in Zanzibar. The results on human behavior and human-vector interaction are presented in accompanying studies [15]. To complement ongoing routine mosquito surveillance carried by ZAMEP, this study was carried out in sites not currently covered by ZAMEP, focusing on hot spots, and utilized higher resolution sampling approach using a different data collection method. The data collection activities were also managed by an electronic-based entomological system making it easier to link these datasets with other sources of data from the same area at the household level.

\section{Methods}

\section{Study Sites}

This study was conducted in Unguja $\left(6.1357^{\circ} \mathrm{S}, 39.3621^{\circ} \mathrm{E}\right)$, the main island in the archipelago of Zanzibar. Zanzibar is currently in the pre-elimination stage and field evidence suggest that remaining cases are focalized, coinciding with high vector abundance [8], and areas where residents frequently travel to mainland Tanzania. Six shehias across 4 districts were selected based on high annual parasite incidence level (i.e., 5/1000 number of new infections per year per 1000 population) and having received IRS in the past year (2016). These six-selected shehia were Miwani, Mbaleni, Bwejuu, Donge-Mchangani, Tunduni, and Charawe as shown in Figure 1. Furthermore, Zanzibar Malaria Elimination Program (ZAMEP) was currently not conducting routine mosquito surveillance in the selected sites.

\section{Study design and sample size.}

Entomological information was collected to assess vector biting and resting patterns, host preferences, and levels of resistance to commonly used insecticides. A total of 135 households across the six shehias consented to participate in mosquito collection. Mosquito collections were carried out indoors and outdoors from 6:00pm-7:00am, using standardized exposure-free volunteer-baited trapping methods (primary outcome measure)[16][17]. Each household was visited eight times over a period of 12 months, from December 2016 - December 2017. This sampling plan was designed to detect effect sizes (differences between proportions of indoor-biting and outdoor-biting vectors) as low as $20 \%$, with at least $80 \%$ power and $95 \%$ confidence limits. As a secondary outcome measure, all Anopheles mosquitoes caught were assessed using enzyme-linked immunosorbent assays (ELISA), to estimate proportions carrying infective Plasmodium falciparum in their salivary glands $[18,19]$. In order to assess preferences of the malaria vectors to biting humans rather than other vertebrates, and to assess any typical resting behaviors of residual transmission vectors, additional mosquito collections in multiple sites including: 
human dwellings, outdoor kitchen enclosures, cowsheds, lawns, latrines, vegetation, and containers found nearby houses. Two artificial resting sites (pit traps) were constructed per site in all sites except Charawe. It was impossible to construct pit traps in Charawe because most of its surface area is covered by stones and grit. In addition to the pit traps, resting buckets were used to collect resting mosquitoes in each household. Furthermore, to assess how residual vector populations respond to and are affected by common indoor insecticidal interventions, malaria vectors present in the different study sites were collected at larval stage and brought to the insectary where first filial generation (F1) was reared to adult level. 100 unfed mosquitoes per batch of 25 females anopheles, aged 3-5 days old were then tested against 10 different types of insecticides (i.e., deltamethrin, permethrin, alpha cypermethrin, lambda cyhalothrin, bendiocarb, pirimiphos-methyl, malathion, fenitrothion, dieldrin, and DDT) currently recommended for vector control [20].

\section{Mosquito Collection}

Mosquitoes were collected inside and outside households using the miniaturized double net trap (DNMini) for 13 hours (6:00 PM - 7:00 AM) as shown in Figure 2

The DN-Mini is an adaptation of the original bed-net trap design [21] which was recently redesigned by Tangena et al., in Lao PDR [16]. The miniaturized double net trap (DN-Mini) was designed to improve comparative mosquito sampling indoors and outdoors while protecting the volunteer collecting mosquitoes (Figure 2). DN-Mini is constructed by using UV-resistant fibreglass netting materials, on a wooden or metal frame and canvas base as illustrated in figure 2 . Its size is $60 \mathrm{~cm}$ width, $100 \mathrm{~cm}$ length and $180 \mathrm{~cm}$ height. It has an inner and outer chamber. Volunteers sit in the protective inner chamber and attract host-seeking mosquitoes. Host-seeking mosquitoes attempting to reach the volunteer in the inner chamber are temporarily trapped between the layers, from where they can be retrieved periodically. The inner wall has multiple sleeves through which the volunteers can safely retrieve the mosquitoes in the outer compartment using siphons. The DN-Mini provides an exposure free method for conducting human baited mosquito sampling contrary to the standard method for mosquito sampling, the human-landing catches (HLC), which does not guarantee the safety of volunteers. Additional collections were done indoors using prokopack aspirators to retrieve mosquitoes from walls and ceiling surfaces, and outdoors using resting bucket traps and artificially constructed pit traps.

\section{Mosquito sampling and processing}

Paper cups containing hourly collection of mosquitoes were placed inside a refrigerator $\left(2-7^{\circ} \mathrm{C}\right)$ for $\leq 5$ mins every morning after a night of collection. The killed mosquitoes were then sorted morphologically into different taxa and sex using dichotomous taxonomic keys [22, 23], and female Anopheles mosquitoes were visually classified as being unfed, partially fed, fully fed, or gravid.

Subsamples of individual female Anopheles mosquitoes from each hourly catch were stored inside a microcentrifuge tube containing a cotton wool and silica gel beneath for further molecular analyses for An. gambiae s.Ispecies identification [24], sporozoite infection status, and blood meal status. In cases where hourly catches contained more than 30 mosquitoes, the first 30 mosquitoes were stored 
individually and all the rest were stored in batches of 10 mosquitoes. The field data and laboratory results were recorded electronically using tablets, linked, cleaned, and stored in a secure web-based database application, the Mosquito Database Management System (MosquitoDB) accessed via www.mosquitodb.io formally known as the Ifakara Entomology Bionformatics System (IEBS). The system was designed based on a generic schema described specifically for the purpose of classifying and processing data and samples relating to most entomological studies [25].

\section{Insecticide susceptibility tests}

To assess how residual vector populations respond to and are affected by common indoor insecticidal interventions, we carried out insecticide susceptibility assays using WHO standard procedures and kits [20] for adult female Anopheles mosquitoes from 4 study sites with the highest mosquito abundances to test for the presence of resistance to commonly used insecticides. The study sites where Anopheles mosquito larvae collection was performed are Mbaleni, Tunduni, Miwani, and DongeMchangani. No any test was performed against mosquitoes from Bwejuu and Charawe sites because during larvae sampling no enough number of Anopheles mosquito larvae were collected that could be reared into adults first filial generation (F1). Larvae collected from the four study sites were brought to the laboratory for rearing into adult mosquitoes of (F1). Batches of 25 adult F1 female Anopheles mosquitoes (3-5 days old) were tested against 10 different types of insecticides that are currently recommended for vector control using discriminating concentrations of impregnated filter papers as follows: deltamethrin $(0.05 \%)$, permethrin $(0.75 \%)$, alpha cypermethrin $(0.05 \%)$, lambda cyhalothrin $(0.05 \%)$, bendiocarb $(0.1 \%)$, pirimiphos-methyl $(0.25 \%)$, malathion (5\%), fenitrothion (1\%), dieldrin (4\%), and DDT (4\%). A total of 100 mosquitoes were exposed per discriminating concentration in four replicates of 25 mosquitoes each and compared to a control with same number of mosquitoes per replicate. In an exposure tube, mosquitoes were held for a total of one hour in intervals of $10,15,20,30,40,50$, and 60 minutes. After the first hour of exposure, mosquitoes were transferred to non-insecticide treated, clean, holding tubes and observed for a further 20 minutes [20]. After 80 minutes (initial $60 \mathrm{~min}+$ further $20 \mathrm{~min}$ ) of knockdown monitoring, all mosquitoes were transferred to non-insecticide treated, clean, holding tubes, kept for 24 hours, and provided with 10\% glucose solution, after which mortality was monitored and recorded. All these procedures were performed in the laboratory under average ambient temperatures of $26 \pm 2^{\circ} \mathrm{C}$ and a relative humidity of $78 \pm 3 \%$ in both bioassay rounds. Percentage knockdown in the observed mosquitoes was recorded immediately for each time interval, and mosquito mortality in each bioassay was expressed as the proportion of dead mosquitoes to total exposed, for each tested insecticide. Execution and interpretation followed WHO test procedures for insecticide resistance monitoring in malaria vector mosquitoes [20].

Furthermore, we separately tested insecticides in commonly used LLINs using cone bioassays for their bio-efficacy and residual activity in killing resistant mosquitoes. LLINs were collected from a few individuals from in our study sites. Five separate sections were cut off from the LLINs and placed into a cone with resistant mosquitoes and the numbers of mosquitoes that are knocked down were recorded.

\section{Statistical analyses}


Data on collected mosquitoes pertaining to An. gambiae s./ were analyzed using R statistical package version 3.6.1[26]. The biting rates for mosquitoes caught indoor versus outdoor were calculated per night as an estimate of risk of exposure of individuals to mosquitoes and a predictor of residual malaria transmission. The difference between indoor and outdoor host-seeking mosquitoes' behaviors were analyzed using Generalized Linear Mixed Models (GLMMs) based on the glmer function under the Ime4 R package. Mosquitoes were modelled as a response variable following a negative binomial distribution for count data to account for the over-dispersion when sampling wild mosquitoes with location (indoor/outdoor) of collection as a fixed numeric variable. A household number was used as a random variable that treated each paired indoor/outdoor collection as an independent collection unit. The round of collection and household ID were used as random variables to best account for sampling bias. Shehias with zero mosquito collection were not included in the model fitting.

For Insecticide susceptibility tests, knock down time and mortality were considered for every discriminating concentration. Mortality was calculated as the percentage of mosquitoes'- dead-' post 24 hours' exposure to insecticide, and the results were assessed according to WHO testing procedure for insecticide resistance monitoring in malaria vectors[20]. Mortality rates between 98 and $100 \%$ indicated full susceptibility, $90-97 \%$ was suggestive of resistance requiring further investigation and mortality rates less than $90 \%$ confirmed the existence of resistance[20]. The Abbot's formula was used to correct mortality rates in the control.

\section{Ethical considerations}

The study approval was granted by the Johns Hopkins Bloomberg School of Public Health Institutional Review Board (IRB No: 00007390), the Ifakara Health Institutional Review Board (IHI/IRB/No:035-2016), and the Zanzibar Medical Research Ethical Council (ZAMREC/0005/OCT/2016) in October 2016. The study was granted an extension by the Ifakara Health Institutional Review Board (IHI/IRB/EXT/No:272017) and the Zanzibar Medical Research Ethical Council (ZAMREC/0001/DEC/2017) in October and December 2017, respectively.

Benefits and potential adverse risks associated with the study were explained to the household members. The head of household consented for mosquito collection to be carried out in his/her household through signing an informed consent form. Volunteers for mosquito collection also consented through signing an informed consent form. Before participating in mosquito collection, volunteers were tested for malaria per round of collection and those who were found to be infected were treated with Coartem ${ }^{\mathrm{TM}}$ (ArtemetherLumafantrine). On top of that, volunteers were provided with chemoprophylaxis Malarone ${ }^{\mathrm{TM}}$ (Atovaquone-Proguanil). In general, volunteers were not exposed to free flying mosquitoes since they were using Miniaturized Double Net that ensured protection as described in method section above. Throughout the study, only one volunteer from Miwani site was tested malaria positive during mosquito sampling. He was given treatment and reported to case management unit (ZAMEP) for further surveillance. 


\section{Results}

\section{Mosquito population and species composition}

A total of 26,365 of mosquitoes were caught of which, $94 \%$ were Culicine mosquitoes and $6 \%$ were Anopheline mosquitoes. Female Anopheles mosquitoes comprised 95.56\% An. gambiae s.l, $4.32 \%$ An. Squamosus, $0.062 \%$ An. pharoensis and $0.062 \%$ An. coustani. PCR analysis on An.gambiae complex indicated that $98.60 \%$ were An. arabiensis, $0.7 \%$ An. merus and $0.7 \%$ were An. gambiae s.s. Number of mosquitoes collected varied per site with Mbaleni having the highest number of mosquito while Charawe and Bwejuu had zero anopheline mosquito catch as shown in Table 1.

Table 1

Showing the of number of mosquitoes caught per site.

\begin{tabular}{|c|c|c|c|c|c|c|c|}
\hline \multirow[t]{2}{*}{ Study site } & \multirow[t]{2}{*}{ Mosquito species } & \multicolumn{3}{|c|}{ Indoor methods } & \multicolumn{2}{|c|}{ Outdoor methods } & \multirow[t]{2}{*}{ Total } \\
\hline & & DN & PK & $\mathrm{CDC}$ & DN & PK & \\
\hline \multirow[t]{2}{*}{ Bwejuu } & An.species & 0 & 0 & 0 & 0 & 0 & 0 \\
\hline & Culicines & 2402 & 86 & 1054 & 2569 & 59 & 6170 \\
\hline \multirow[t]{2}{*}{ Charawe } & An. species & 0 & 0 & 0 & 0 & 0 & 0 \\
\hline & Culicines & 1701 & 17 & 496 & 1531 & 73 & 3818 \\
\hline \multirow[t]{2}{*}{ Tunduni } & An. species & 0 & 1 & 2 & 0 & 8 & 11 \\
\hline & Culicines & 245 & 8 & 60 & 294 & 133 & 740 \\
\hline \multirow[t]{2}{*}{ Miwani } & An. species & 24 & 2 & 62 & 90 & 85 & 263 \\
\hline & Culicines & 955 & 20 & 734 & 1103 & 260 & 3072 \\
\hline \multirow[t]{2}{*}{ Donge Mchangani } & An. species & 9 & 0 & 3 & 21 & 213 & 246 \\
\hline & Culicines & 2572 & 12 & 1320 & 3110 & 210 & 7224 \\
\hline \multirow[t]{3}{*}{ Mbaleni } & An. species & 62 & 6 & 766 & 137 & 106 & 1077 \\
\hline & Culicines & 904 & 12 & 1721 & 1005 & 102 & 3744 \\
\hline & Overall Total & 8874 & 164 & 6218 & 9860 & 1249 & 26365 \\
\hline
\end{tabular}

\section{Biting pattern and resting preferences}

Using a standardized free exposure trap (DN-Mini), a large number of Anopheline mosquitoes were collected outdoor compared to indoor (248 versus 95 respectively) as shown in Table 2. 
Table 2

Outdoor vs Indoor Anopheline mosquitoes caught using DN-Mini.

\begin{tabular}{|llll|}
\hline An. Specie & Indoor & Outdoor & Total \\
\hline An. gambiae s.I & 90 & 199 & 289 \\
\hline An. squamosus & 5 & 48 & 53 \\
\hline An. coustani & 0 & 1 & 1 \\
\hline An. pharoensis & 0 & 0 & 0 \\
\hline Overall Total & 95 & 248 & 343 \\
\hline
\end{tabular}

The difference in An. gambiae s./ proportions between indoor and outdoor - mosquito collections were compared using GLLMs assuming a negative binomial distribution. The proportion of outdoor hostseeking mosquitoes was computed as the number of mosquito collected from outdoor divided by the overall number of mosquitoes collected indoor and outdoor using DN-Mini. The analysis was only performed on Miwani and Mbaleni. Figure 3 presents the mean number of An. gambiae s.l. collected per night indoor and outdoor for the three shehias with reasonable number of mosquitoes caught.

In Miwani, the proportion of mosquitoes caught outdoor is statistically significant and nearly double (RR: $1.942[1.03,3.772], 95 \% \mathrm{Cl}, \mathrm{p}$ value $<0.05$ ) as compared to indoor (RR: $0.000254\left[6.77 \star 10^{\wedge}-6,0.00244\right]$, $95 \% \mathrm{Cl}, \mathrm{p}$ value $<0.001)$. Similarly, in Mbaleni, the proportional of mosquito caught outdoor is statistically significant and double (RR: 2.42 [1.41,4.25], 95\% Cl, p value< 0.001 ) compared to indoor (RR: 0.000123 $\left[1.82^{\wedge}-07,0.00198\right], 95 \% \mathrm{Cl}$, p value< 0.001$)$.

In addition, $90 \%$ of collected mosquitoes were caught during wet season. A similar statistical model used above was used to examine the difference in mosquito bites between dry and wet season by using season as a fixed variable for the same three shehias. In Miwani, the mosquito caught during the dry season (RR: $3.5^{\wedge}-05\left[3.39^{\wedge}-07,7.28^{\wedge}-04\right], 95 \% \mathrm{Cl}, \mathrm{p}$ value $<0.001$ ) is significantly different from the wet

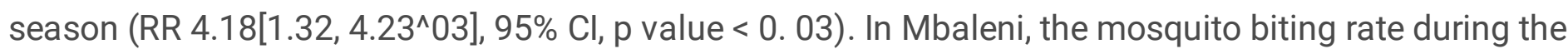
dry season (RR: $0.000124\left[1.2^{\wedge}-07,5.23^{\wedge}-03\right], 95 \% \mathrm{Cl}, \mathrm{p}$ value $<0.001$ ) is significantly different from the wet season (RR 4.66[4.64^-03, 2.9^03], 95\% $\mathrm{Cl}$, p value $<0.55)$.

As indicated in Figure 4, the highest frequency of mosquito bites occurred at $2100 \mathrm{hrs}$ and $0500 \mathrm{hrs}$ outdoor but at $0100 \mathrm{hrs}$ and $0200 \mathrm{hrs}$ indoor in Mbaleni (panel A), at $0100 \mathrm{hrs}$ and $0200 \mathrm{hrs}$ outdoor but at $0000 \mathrm{hrsindoor} \mathrm{in} \mathrm{Donge} \mathrm{Mchangani} \mathrm{(panel} \mathrm{B),} \mathrm{at} 1800 \mathrm{hrs}$ and $0300 \mathrm{hrs}$ outdoor but at $0200 \mathrm{hrs}$ indoor in Miwani (panel C). While, the lowest frequency of mosquito bites occurred indoors in the early evening and early morning.

Overall for the three sites, the mean numbers of An. gambiae s./ caught by DN-Mini show that the highest frequency of mosquito bites occurred at $1800 \mathrm{hrs}, 2100 \mathrm{hrs}, 0100 \mathrm{hrs}, 0200 \mathrm{hrs}$, and $0500 \mathrm{hrs}$ for outdoor 
biting mosquitoes and at $0000 \mathrm{hrs}, 0100 \mathrm{hrs}$, and $0200 \mathrm{hrs}$ for indoor biting mosquitoes. While, the lowest frequency of mosquito bites occurred indoors in the early evening and early morning (Fig. 4).

Furthermore, under this study outdoor resting behavior of mosquitoes was also assessed. The artificially created resting sites (pit-traps) collected 415 Anopheline mosquitoes while the other resting traps (resting buckets) placed indoors did not collect any Anopheline mosquitoes. However, indoor and outdoor resting behavior could not be directly compared as different trapping methods were used.

\section{Sporozoite rate and blood meal host preferences.}

All mosquitoes subjected to sporozoite ELISA analysis were negative with malaria sporozoite. Using the same technique but of different procedures to quickly analyze the blood meal host preferences it is observed that approximately $60 \%$ of blood-fed mosquitoes obtained blood from domestic animals (Goat, Bovine, Dog and Chicken) compared to $40 \%$ from human blood (Figure 5). Table 3 below presents the distribution of non-human hosts from the six shehias based on the survey from the human behavior component of the study.

Table 3

Distribution of non-human hosts from the study sites.

\begin{tabular}{|lllllll|}
\hline Study sites & \multicolumn{3}{l}{ Non-human host } & & & \\
\cline { 2 - 7 } & Chicken & Duck & Goat & Cow & Cat & Pigeon \\
\hline Miwani & 115 & 2 & 4 & 16 & 0 & 6 \\
\hline Mbaleni & 241 & 22 & 13 & 43 & 2 & 5 \\
\hline Bwejuu & 5 & 7 & 0 & 1 & 0 & 0 \\
\hline Donge Mchangani & 436 & 23 & 3 & 41 & 0 & 0 \\
\hline Tunduni & 140 & 6 & 12 & 33 & 0 & 3 \\
\hline Charawe & 68 & 0 & 0 & 12 & 0 & 0 \\
\hline Overall Total & 1005 & 60 & 32 & 146 & 2 & 14 \\
\hline
\end{tabular}

Anopheline mosquitoes feed on human blood relatively equally indoor and outdoor (Fig. 5). Contrary to equal balance of mosquitoes with human blood, more mosquitoes with blood from Goat, Bovine, Dog and Chicken were sampled from outdoor dwellings.

\section{Mosquito susceptibility and intensity/level of Insecticide resistance}


Mosquitoes tested against selected insecticides from the pyrethroid class resulted in non-uniform resistances status across the four sites. Under pyrethroid class, mosquitoes were found susceptible to Permethrin (0.05\%) at Donge-Mchangani North part of Unguja, Mbaleni and Tunduni in Central part of Unguja. Apart from permethrin $(0.05 \%)$, the tested mosquitoes were also susceptible to Deltamethrin $(0.05 \%)$ at Mbaleni Central part of Unguja. Furthermore, mosquitoes at different sites displayed middle outcome lying between susceptible and resistant called possible resistance indication according to WHO insecticide susceptibility procedures update 2016. Mosquitoes that were tested and indicated suggestive resistance were tested against Deltamethrin $(0.05 \%)$ at Donge-Mchangani North part of Unguja, Lambdacyhalothrin $(0.05 \%)$ at both Mbaleni and Tunduni in Central part of Unguja.

Moreover, mosquitoes were tested and confirmed resistant against lambda-cyhalothrin (0.05\%) at both Donge-Mchangani and Miwani, alpha-cypermethrin (0.05\%) at DongeMchangani, Mbaleni, Miwani, and Tunduni, and permethrin (0.75\%) at Miwani as shown in Table 4-7.

Contrary to outcome variation observed under Pyrethroid class insecticides, representative insecticides from the other three classes of insecticides (i.e. organochlorine, organophosphate and carbamate) were also tested and resulted in uniform outcomes where all the tested mosquitoes were susceptible against the insecticides to which they were exposed (Table 4-7). Similarly, to susceptibility tests outcomes, the intensity of resistance test results was non-uniform. The intensity of resistance varied across the four sites and the insecticide tested.

Table 4

Susceptibility status at Mbaleni site.

\begin{tabular}{|c|c|c|c|c|}
\hline Insecticide class & Insecticide name & $\begin{array}{l}\text { Knockdown (\%) } \\
60 \text { mins }\end{array}$ & $\begin{array}{l}\text { Mortality (\%) } \\
\text { 24hrs }\end{array}$ & $\begin{array}{l}\text { Susceptibility } \\
\text { status }\end{array}$ \\
\hline \multirow[t]{4}{*}{ Pyrethroid } & Deltamethrin $(0.05 \%)$ & 100 & 100 & Susceptible \\
\hline & Permethrin (0.75\%) & 100 & 100 & Susceptible \\
\hline & $\begin{array}{l}\text { Lambda-cyhalothrin } \\
(0.05 \%)\end{array}$ & 100 & 97 & $\begin{array}{l}\text { Possible } \\
\text { resistance }\end{array}$ \\
\hline & $\begin{array}{l}\text { Alpha-cypermethrin } \\
(0.05 \%)\end{array}$ & 88 & 60 & $\begin{array}{l}\text { Confirmed } \\
\text { resistance }\end{array}$ \\
\hline Carbamates & Bendiocarb (0.1\%) & 100 & 100 & Susceptible \\
\hline \multirow[t]{3}{*}{ Organophosphates } & $\begin{array}{l}\text { Pirimiphos-methyl } \\
(0.25 \%)\end{array}$ & 96 & 100 & Susceptible \\
\hline & Malathion (5\%) & 100 & 100 & Susceptible \\
\hline & Fenitrithion (1\%) & 80 & 100 & Susceptible \\
\hline \multirow[t]{2}{*}{ Organochlorine } & Dieldrin (4\%) & 99 & 100 & Susceptible \\
\hline & DDT (4\%) & 100 & 100 & Susceptible \\
\hline
\end{tabular}


Table 5

Susceptibility status at Miwani site.

\begin{tabular}{|c|c|c|c|c|}
\hline Insecticide class & Insecticide name & $\begin{array}{l}\text { Knockdown (\%) } \\
60 \mathrm{~min}\end{array}$ & $\begin{array}{l}\text { Mortality (\%) } \\
24 \text { hrs }\end{array}$ & $\begin{array}{l}\text { Susceptibility } \\
\text { status }\end{array}$ \\
\hline \multirow[t]{4}{*}{ Pyrethroid } & Deltamethrin (0.05\%) & 99 & 73 & $\begin{array}{l}\text { Confirmed } \\
\text { resistance }\end{array}$ \\
\hline & Permethrin (0.75\%) & 14 & 21 & $\begin{array}{l}\text { Confirmed } \\
\text { resistance }\end{array}$ \\
\hline & $\begin{array}{l}\text { Lambda-cyhalothrin } \\
(0.05 \%)\end{array}$ & 93 & 82 & $\begin{array}{l}\text { Confirmed } \\
\text { resistance }\end{array}$ \\
\hline & $\begin{array}{l}\text { Alpha-cypermethrin } \\
(0.05 \%)\end{array}$ & 95 & 97 & $\begin{array}{l}\text { Possible } \\
\text { resistance }\end{array}$ \\
\hline Carbamates & Bendiocarb (0.1\%) & 100 & 100 & Susceptible \\
\hline \multirow[t]{3}{*}{ Organophosphates } & $\begin{array}{l}\text { Pirimiphos-methyl } \\
(0.25 \%)\end{array}$ & 84 & 100 & Susceptible \\
\hline & Malathion (5\%) & 100 & 100 & Susceptible \\
\hline & Fenitrithion (1\%) & 68 & 100 & Susceptible \\
\hline \multirow[t]{2}{*}{ Organochlorine } & Dieldrin (4\%) & 92 & 100 & Susceptible \\
\hline & DDT (4\%) & 100 & 100 & Susceptible \\
\hline
\end{tabular}


Table 6

Susceptibility status at Tunduni site.

\begin{tabular}{|c|c|c|c|c|}
\hline Insecticide class & Insecticide name & $\begin{array}{l}\text { Knockdown (\%) } \\
60 \mathrm{~min}\end{array}$ & $\begin{array}{l}\text { Mortality (\%) } \\
24 \mathrm{hrs}\end{array}$ & $\begin{array}{l}\text { Susceptibility } \\
\text { status }\end{array}$ \\
\hline \multirow[t]{4}{*}{ Pyrethroid } & Deltamethrin (0.05\%) & 76 & 26 & $\begin{array}{l}\text { Confirmed } \\
\text { resistance }\end{array}$ \\
\hline & Permethrin (0.75\%) & 95 & 100 & Susceptible \\
\hline & $\begin{array}{l}\text { Lambda-cyhalothrin } \\
(0.05 \%)\end{array}$ & 97 & 96 & $\begin{array}{l}\text { Possible } \\
\text { resistance }\end{array}$ \\
\hline & $\begin{array}{l}\text { Alpha-cypermethrin } \\
(0.05 \%)\end{array}$ & 79 & 96 & Susceptible \\
\hline Carbamates & Bendiocarb $(0.1 \%)$ & 99 & 100 & Susceptible \\
\hline \multirow[t]{3}{*}{ Organophosphates } & $\begin{array}{l}\text { Pirimiphos-methyl } \\
(0.25 \%)\end{array}$ & 93 & 100 & Susceptible \\
\hline & Malathion (5\%) & 100 & 100 & Susceptible \\
\hline & Fenitrithion (1\%) & 58 & 100 & Susceptible \\
\hline \multirow[t]{2}{*}{ Organochlorine } & Dieldrin (4\%) & 94 & 100 & Susceptible \\
\hline & DDT (4\%) & 100 & 100 & Susceptible \\
\hline
\end{tabular}


Table 7

Susceptibility status at Donge Mchangani site.

\begin{tabular}{|c|c|c|c|c|}
\hline Insecticide class & Insecticide name & $\begin{array}{l}\text { Knockdown (\%) } \\
60 \mathrm{~min}\end{array}$ & $\begin{array}{l}\text { Mortality (\%) } \\
24 \mathrm{hrs}\end{array}$ & $\begin{array}{l}\text { Susceptibility } \\
\text { status }\end{array}$ \\
\hline \multirow[t]{4}{*}{ Pyrethroid } & Deltamethrin (0.05\%) & 97 & 97 & $\begin{array}{l}\text { Possible } \\
\text { resistance }\end{array}$ \\
\hline & Permethrin (0.75\%) & 100 & 100 & Susceptible \\
\hline & $\begin{array}{l}\text { Lambda-cyhalothrin } \\
(0.05 \%)\end{array}$ & 83 & 85 & $\begin{array}{l}\text { Confirmed } \\
\text { resistance }\end{array}$ \\
\hline & $\begin{array}{l}\text { Alpha-cypermethrin } \\
(0.05 \%)\end{array}$ & 94 & 81 & $\begin{array}{l}\text { Confirmed } \\
\text { resistance }\end{array}$ \\
\hline Carbamates & Bendiocarb $(0.1 \%)$ & 100 & 100 & Susceptible \\
\hline \multirow[t]{3}{*}{ Organophosphates } & $\begin{array}{l}\text { Pirimiphos-methyl } \\
(0.25 \%)\end{array}$ & 89 & 100 & Susceptible \\
\hline & Malathion (5\%) & 100 & 100 & Susceptible \\
\hline & Fenitrithion (1\%) & 96 & 100 & Susceptible \\
\hline \multirow[t]{2}{*}{ Organochlorine } & Dieldrin (4\%) & 100 & 100 & Susceptible \\
\hline & DDT (4\%) & 100 & 100 & Susceptible \\
\hline
\end{tabular}

Similar to susceptibility test outcomes, the intensity of resistance test results was non-uniform. The intensity of resistance varied across the four sites and the insecticide tested as shown in Table 8. 
Table 8

Variation of intensity of resistance across the four study sites.

\begin{tabular}{|lll|}
\hline Study site & Insecticide name & Intensity of resistance \\
\hline \multirow{2}{*}{ Monge } & Deltamethrin & Low intensity \\
\cline { 2 - 3 } & Alpha-cypermethrin & Low intensity \\
\hline Miwani & Lamba-cyhalothrin & Moderate to high intensity \\
\cline { 2 - 3 } & Alpha-cypermethrin & Moderate to high intensity \\
\cline { 2 - 3 } & Lamba-cyhalothrin & Low intensity \\
\cline { 2 - 3 } & Permethrin & Low intensity \\
\cline { 2 - 3 } & Deltamethrin & Moderate to high intensity \\
\hline Tunduni & Alpha-cypermethrin & Low intensity \\
\cline { 2 - 3 } & Lamba-cyhalothrin & Low intensity \\
\cline { 2 - 3 } & Deltamethrin & Low intensity \\
\cline { 2 - 3 } &
\end{tabular}

Generally, the intensity of resistance across the four sites ranged from low intensity and, moderate to high intensity e.g. mosquitoes tested against Deltamethrin (0.25\%) at Miwani, Tunduni, and Donge-Mchangani had different outcome between the mentioned sites. Mosquitoes tested at Miwani resulted in moderate to high-intensity resistance while mosquitoes exposed to deltamethrin $(0.25 \%)$ at Donge-Mchangani and Tunduni displayed low-intensity resistance. This kind of variation is seen also against other insecticides and at different sites as presented in Table 8.

\section{Discussion}

These findings highlight potential entomological drivers contributing to residual malaria transmission in Zanzibar and the testing of complementary novel techniques that can be used to target outdoor biting and resting mosquitoes. Key findings include: a high proportion of outdoor biting and resting behaviour, high levels of zoophilic behaviour, and varying levels of pyrethroid resistance across sites. All these factors could contribute to ongoing local malaria transmission in Zanzibar.

After eight rounds of indoor and outdoor mosquito collection in 135 households across six Shehias in four districts only a total of 704 malaria vectors were collected. In most trap nights, the average number of malaria vectors caught was zero especially in dry season. This indicates that the mosquito density is very low in Zanzibar especially in the dry season. ZAMEP has also reported the very low numbers of malaria vectors collection from 2012 to 2018 (ZAMEP reports, unpublished data). Malaria vector reduction is likely to be attributed to the continuous use of LLINs as well as implementation of IRS in 
areas with high density of malaria vectors[27]. In addition, a majority of malaria vectors were $A n$. Arabiensis (98.4\%), mostly caught outdoors (85\%), which is an opportunistic species [28-30] and it is not surprising that out of 173 blood-fed mosquitoes-39.30\% obtained blood from human and $60.70 \%$ from non-human hosts (i.e., 34.68\%, 21.97\%, 3.47\%,and 0.58\% from Goat, Bovine, Dog and Chicken respectively). In general, a large significant number of mosquitoes with blood from non-human hosts were sampled from outdoor dwellings. In contrast, mosquitoes fed equally outdoor (50\%) and indoor (50\%) on human blood- exhibiting An. arabiensis feeding behavior [31, 32]. Similar findings on outdoor and indoor biting preference and malaria vector species composition were also obtained by ZAMEP as presented in their entomological report from 2012 to 2018 - indicating high number of An. arabiensis compared to An.gambiae s.s.[33]. This significant reduction of An. gambiae s.s in the island might be due to wide use of indoor interventions (i.e., (LLINs) and (IRS)) [27]. An. arabiensis is becoming a major malaria vector in Zanzibar and its increasing role in malaria transmission has also been reported in various studies in Tanzania [34] and in Kenya [35]. Sporozoite ELISA analysis indicates that all mosquitoes tested were negative for the malaria parasite. Nevertheless, significant outdoor biting behaviour can potentially indicate the high risk of outdoor malaria transmission in Zanzibar. In addition, it was also observed that the artificially created outdoor resting sites collected a large numbers of Anopheline mosquitoes as compared to the number collected resting indoors- and this has also been demonstrated in ZAMEP's entomological reports (2013- 2017). This might also highlight the mosquito behavior change from resting in indoor dwellings e.g. ceiling, walls to outdoor dwelling like the dug hole and other areas with favorable resting conditions e.g. darkness. The implementation of indoor core interventions i.e. LLINs and/or IRS as previously demonstrated in some studies as one of the driving forces of mosquitoes behavioral change [31, 36, 37]).

In understanding that insecticide resistance may impact the effectiveness LLINs and IRS which are widely used in Zanzibar -insecticide resistance tests based on WHO procedures were carried out [20]. The tests were carried on commonly used insecticide based on samples from only four sites with the highest mosquito densities. The findings indicate that testing outcomes for pyrethroid class insecticides across the four sites were not uniform. The susceptibility tests indicated that mosquitoes were susceptible to some insecticides, displayed possible resistance to others depending on the insecticide tested. Insecticide intensity outcomes also varied across the study sites. Generally, the intensity of resistance across the four sites ranged from low intensity, moderate to high intensity. The susceptibility and intensity variation are also reported in ZAMEP reports for Unguja site but it is uniform in Pemba study sites where mosquitoes have displayed high level of resistance to pyrethroid class insecticide (ZAMEP report 2018). These variations might be explained by several facts including tendency of net use in the particular site, level of urbanization as well as agricultural activities. The use of different insecticides in agricultural activities might trigger high selection pressure of insecticide resistance in one site compared to another site [38,39]. In contrast, mosquitoes were susceptible to all representative insecticides from the other three classes (i.e., organochlorine, organophosphate and carbamate) across all the four sites. The insecticide resistance carried out by ZAMEP in 2018 in three different sites in Unguja are consistent with our findings (ZAMEP report 2018, unpublished data).Insecticide resistance in 
African malaria vectors have also been reported in other malaria endemic settings [40-44]. The resistance levels and mechanisms to African malaria vectors have been documented all over in malaria endemic settings[44-47]. The wide spread of insecticide resistance affects both malaria control and transmission[48-51].This on-going mosquito resistance to pyrethroids highlights the need to consider other options for the insecticide used for LLINs and IRS programs.

Recently, the addition of a synergist, piperonyl butoxide (PBO), to pyrethroid nets has been investigated. Available evidence suggest that pyrethroid-PBO nets are more effective than standard pyrethroid nets in settings with insecticide resistance[52,53]. While pyrethroid-PBO nets can help to maintain protection in some settings, they should not be considered a tool for insecticide resistance management, rather broader insecticide resistance management strategies are essential [WHO, 2017b].

Most entomological studies will normally calculate and report entomological inoculation rate (EIR) which is the practical indicator of human exposure mosquitoes bites infected with transmissible sporozoitestage malaria parasites[54].This indicator can be used to assess the impact of vector control tools (VCTs) and it is important for VCTs to sustainably reduce EIRs to levels below 1 in order to interrupt malaria transmission[55]. In this study, EIR was not calculated due to the absence of any sporozoite positive mosquito. The findings from ZAMEP's mosquito routine collections in Zanzibar indicated that five sporozoite positive Anopheles arabiensis mosquitoes detected by CSP ELISA have been confirmed in the last six years (2012 -2018) in Unguja. However, no positive sporozoite mosquitoes have been detected in Pemba in the same period, (ZAMEP report, unpublished data). This indicates that the transmission is declining to the extent that it is becoming difficult to estimate EIR or it might require using advanced techniques for sporozoites detection in low transmission settings.

A key limitation of the study was the inability to detect sporozoite rates from blood-fed mosquitoes collected. CSP ELISA was used for sporozoite detection and the study found no sporozoite positive mosquitoes. As a result, it was not possible to calculate the current EIR value (given sporozoite infection rate as a factor). This could reflect the characteristically low transmission of malaria in Zanzibar along with Anopheles mosquito density. Though, we anticipate that more advanced sporozoite detection methods (i.e., PCR ELISA) may have allowed for better detection of sporozoite rates. Higher resolution sampling in hot spot areas could be helpful in catching sporozite positive mosquitoes. These findings illustrate that, in areas of persistent low malaria transmission more powerful methods may be needed to detect sporozoite infection rates. In similar settings, entomological studies alone may be inadequate for making a conclusion regarding the presence of local malaria transmission but will require using other techniques such as detection of malaria parasite movement through genetic sequencing.

Another limitation of the study methodology is associated with the type of trap used to collect mosquitoes. Hourly mosquito collections were carried out in the peri-domestic setting using the double net trap (MD-Mini) [16] instead of human landing catch (HLC) which is often considered the gold standard[56]. Therefore, the recorded biting rates may have been impacted by the trapping method used. However, a previous study showed no significant difference between number of Anopheles mosquito 
caught by HLC and DN-Mini [16].The double net trap was used to increase the safety of volunteers during the collection by ensuring that they are not freely exposed to mosquito bites.

Despite these limitations, this study has contributed to understanding the magnitude and entomological drivers contributing to the residual malaria transmission in Zanzibar and areas with similar transmission settings. The study suggests increased outdoor-biting proportions, shifts in peak biting times to earlyevening hours, and the rise of pyrethroid-resistant Anopheles vectors. Therefore, the findings from this study highlight the need to consider using bednets treated with other insecticide (e.g., a LLIN that incorporates a synergist piperonyl butoxide (PBO) [53], different insecticide for IRS programs in Zanzibar[53] and/or rotation of insecticide application mode [44], and proper implementation of larviciding which target mosquitoes at aquatic stages [57-59]. In addition, complementary tools enhancing indoor protection and especially targeting outdoor transmission have the potential to contribute to eliminating residual malaria transmission in Zanzibar.

\section{Conclusion}

This study suggests that in contexts such as Zanzibar - testing of novel techniques to complement indoor protection and especially targeting outdoor biting and/or resting mosquitoes as well as immature mosquitoes, may be warranted in these settings. If found to be effective, these suggested approaches would complement existing interventions that target mosquitoes biting and/or resting indoors. The study also highlights the need to consider insecticide resistance in selection of core vector control interventions.

\section{Abbreviations}

LLINS: Long lasting Insecticide treated Nets,

IRS: Indoor Residual Spraying

DN: Double Net

PCR: Polymerase Chain Reaction

ELISA: Enzyme- linked Immunosorbent Assay

WHO: World Health Organization

PBO: Piperonyl butoxide

RDTs: Rapid diagnostic tests

ACTs: Artemisinin-based combination therapy

An: Anopheles 
ZAMEP: Zanzibar Malaria Elimination Program

HLC: Human-landing catch

IEBS: Ifakara Entomology Bionformatics System

DDT: Dichlorodiphenyltrichloroethane

IRB: Institutional Review Board

ZAMREC: Zanzibar Medical Research Ethical Council

EIR: Entomological inoculation rate

VCTs: Vector Control Tools

F1: First filial generation

\section{Declarations}

\section{Ethics approval and consent to participate}

The study approval was granted by the Johns Hopkins Bloomberg School of Public Health Institutional Review Board (IRB No: 00007390), the Ifakara Health Institutional Review Board (IHI/IRB/No:035-2016), and the Zanzibar Medical Research Ethical Council (ZAMREC/0005/OCT/2016) in October 2016. The study was granted an extension by the Ifakara Health Institutional Review Board (IHI/IRB/EXT/No:272017) and the Zanzibar Medical Research Ethical Council (ZAMREC/0001/DEC/2017) in October and December 2017, respectively. Volunteers for mosquito collection also had to consent through signing of an informed consent form.

\section{Consent for publication}

Not applicable

\section{Availability of data and materials}

The dataset supporting the conclusions of this article is available upon request in MosquitoDB application accessible via https://www.mosquitodb.io

\section{Competing interests}

The authors have declared that they have no competing interests.

\section{Funding}


This work was made possible by the generous support of the American people through the United States Agency for International Development (USAID) and the President's Malaria Initiative (PMI) under the terms of USAID/JHU Cooperative Agreement No. AID-OAA-A-14-00057 (Vector-Works Project). The contents are the responsibility of the authors and do not necessarily reflect the views of USAID or the United States Government. This work was supported, in part, by the Bill \& Melinda Gates Foundation [INV-016807]. Under the grant conditions of the Foundation, a Creative Commons Attribution 4.0 Generic License has already been assigned to the Author Accepted Manuscript version that might arise from this submission.

\section{Authors' Contributions}

FO, AM, BT, GG, AA, and SK conceived and designed the study, RM, BT, DM, KM, AL, GC, AJ, JM, KH, FA, $A A$, and SK conducted the study, DM and SK, designed and developed MosquitoDB, RM, DM, HN and SK performed the data analysis. All authors read and approved the final manuscript.

\section{Acknowledgements}

The authors would like to acknowledge the hard work and dedication of the data collection teams from the six Shehias. The authors would also like uniquely to thank Mr. Tongoa, who worked hand-in-hand with the fieldwork day and night to ensure that the data collection process was successful. This work would not have been possible without the participation of household members who welcomed the study team into their homes, the support and partnership of community leaders in the data collection sites, and the technical leadership and commitment demonstrated by the Zanzibar National Malaria Elimination Program.

\section{References}

1. O'Meara WP, Mangeni JN, Steketee R, Greenwood B. Changes in the burden of malaria in subSaharan Africa. Lancet Infect Dis. 2010;10:545-55.

2. Fegan GW, Noor AM, Akhwale WS, Cousens S, Snow RW. Effect of expanded insecticide-treated bednet coverage on child survival in rural Kenya: a longitudinal study. Lancet. 2007;370:1035-9.

3. Noor AM, Kinyoki DK, Mundia CW, Kabaria CW, Mutua JW, Alegana VA, et al. The changing risk of Plasmodium falciparum malaria infection in Africa: 2000-10: a spatial and temporal analysis of transmission intensity. Lancet. 2014;383:1739-47.

4. Bhatt S, Weiss DJ, Cameron E, Bisanzio D, Mappin B, Dalrymple U, et al. The effect of malaria control on Plasmodium falciparum in Africa between 2000 and 2015. Nature. 2015;526:207.

5. ZMCP. Malaria elimination in Zanzibar: a feasibility assessment. Ministry of Health and Social Welfare Zanzibar City, Zanzibar; 2009.

6. Thomas MA. Britain since 1939: Progress and Decline. Hist Rev New Books. 2010;25:23-4.

7. Killeen GF. Characterizing, controlling and eliminating residual malaria transmission. Malar J. 2014;13:330. 
8. Hardy A, Mageni Z, Dongus S, Killeen G, Macklin MG, Majambare S, et al. Mapping hotspots of malaria transmission from pre-existing hydrology, geology and geomorphology data in the preelimination context of Zanzibar, United Republic of Tanzania. Parasit Vectors. 2015;8:41.

9. Lengeler $\mathrm{C}$. Insecticide-treated bed nets and curtains for preventing malaria. Cochrane Database Syst Rev. 2004;1-46.

10. Pluess B, Tanser FC, Lengeler C, Sharp BL. Indoor residual spraying for preventing malaria. Cochrane database Syst Rev. John Wiley \& Sons, Ltd; 2010;

11. Killeen GF, Smith TA, Ferguson HM, Mshinda H, Abdulla S, Lengeler $C$, et al. Preventing childhood malaria in Africa by protecting adults from mosquitoes with insecticide-treated nets. PLoS Med. 2007;4:e229.

12. Haji KA, Thawer NG, Khatib BO, Mcha JH, Rashid A, Ali AS, et al. Efficacy, persistence and vector susceptibility to pirimiphos-methyl (Actellic ${ }^{\circledR} 300 \mathrm{CS}$ ) insecticide for indoor residual spraying in Zanzibar. Parasit Vectors. 2015;8:628.

13. Haji KA, Khatib BO, Smith S, Ali AS, Devine GJ, Coetzee M, et al. Challenges for malaria elimination in Zanzibar: pyrethroid resistance in malaria vectors and poor performance of long-lasting insecticide nets. Parasit Vectors. 2013;6:82.

14. Thawer NG, Ngondi JM, Mugalura FE, Emmanuel I, Mwalimu CD, Morou E, et al. Use of insecticide quantification kits to investigate the quality of spraying and decay rate of bendiocarb on different wall surfaces in Kagera region, Tanzania. Parasit Vectors. 2015;8:242.

15. Monroe A, Mihayo K, Okumu F, Finda M, Moore S, Koenker $H$, et al. Human behaviour and residual malaria transmission in Zanzibar: findings from in-depth interviews and direct observation of community events. Malar J. 2019;18:1-13.

16. Tangena J-AA, Thammavong P, Hiscox A, Lindsay SW, Brey PT. The Human-Baited Double net trap: An Alternative to Human Landing Catches for Collecting Outdoor Biting Mosquitoes in Lao PDR. PLoS One. 2015;10:1-13.

17. Limwagu AJ, Kaindoa EW, Ngowo HS, Hape E, Finda M, Mkandawile G, et al. Using a miniaturized double-net trap (DN-Mini) to assess relationships between indoor-outdoor biting preferences and physiological ages of two malaria vectors, Anopheles arabiensis and Anopheles funestus. Malar J. 2019;18:282.

18. Beier JC, Copeland RS, Onyango FK, Asiago CM, Ramadhan M, Koech DK, et al. Plasmodium species identification by ELISA for sporozoites removed from dried dissection slides. J Med Entomol. 1991;28:533-6.

19. Durnez L, Van Bortel W, Denis L, Roelants P, Veracx A, Trung HD, et al. False positive circumsporozoite protein ELISA: a challenge for the estimation of the entomological inoculation rate of malaria and for vector incrimination. Malar J. 2011;10:195.

20. World Health Organization (WHO). Test procedures for insecticide resistance monitoring in malaria vector mosquitoes. 2013. 
21. WHO. Manual on practical entomology in Malaria. Part II. Methods and techniques. WHO Div Malar other Parasit Dis. 1975;

22. Gillies M., Meillon B De. The Anophelinae of Africa south of the Sahara: Ethiopian zoogeographical region. 2nd ed. South African Institute for Medical Research; 1968.

23. Gillies MT, Coetzee M. A Supplement to the Anophelinae of the South of the Sahara (Afrotropical Region). South African Institute for Medical Research; 1987.

24. Scott JA, Brogdon WG, Collins FH. Identification of single specimens of the Anopheles gambiae complex by the polymerase chain reaction. Am J Trop Med Hyg. 1993;49:520-9.

25. Kiware SS, Russell TL, Mtema ZJ, Malishee AD, Chaki P, Lwetoijera D, et al. A generic schema and data collection forms applicable to diverse entomological studies of mosquitoes. Source Code Biol Med. 2016;11:4.

26. Team RC. R: A language and environment for statistical computing. Vienna, Austria; 2013;

27. Derua YA, Alifrangis M, Hosea KM, Meyrowitsch DW, Magesa SM, Pedersen EM, et al. Change in composition of the Anopheles gambiae complex and its possible implications for the transmission of malaria and lymphatic filariasis in north-eastern Tanzania. Malar J. 2012;11:188.

28. Abdalla H, Matambo TS, Koekemoer LL, Mnzava AP, Hunt RH, Coetzee M. Insecticide susceptibility and vector status of natural populations of Anopheles arabiensis from Sudan. Trans R Soc Trop Med Hyg. 2008;102:263-71.

29. Asale A, Duchateau L, Devleesschauwer B, Huisman G, Yewhalaw D. Zooprophylaxis as a control strategy for malaria caused by the vector Anopheles arabiensis (Diptera: Culicidae): a systematic review. Infect Dis poverty. 2017;6:160.

30. Fuller DO, Parenti MS, Hassan AN, Beier JC. Linking land cover and species distribution models to project potential ranges of malaria vectors: an example using Anopheles arabiensis in Sudan and Upper Egypt. Malar J. 2012;11:264.

31. Mahande A, Mosha F, Mahande J, Kweka E. Feeding and resting behaviour of malaria vector, Anopheles arabiensis with reference to zooprophylaxis. Malar J. 2007;6:100.

32. Tirados I, Costantini C, Gibson G, Torr SJ. Blood-feeding behaviour of the malarial mosquito Anopheles arabiensis: implications for vector control. Med Vet Entomol. 2006;20:425-37.

33. ZAMEP 2012 -2017 vector COMPOSITION.

34. Lwetoijera DW, Harris C, Kiware SS, Dongus S, Devine GJ, McCall PJ, et al. Increasing role of Anopheles funestus and Anopheles arabiensis in malaria transmission in the Kilombero Valley, Tanzania. Malar J. 2014;13:331.

35. Mwangangi JM, Muturi EJ, Muriu SM, Nzovu J, Midega JT, Mbogo C. The role of Anopheles arabiensis and Anopheles coustani in indoor and outdoor malaria transmission in Taveta District, Kenya. Parasit Vectors. 2013;6:114.

36. Russell TL, Govella NJ, Azizi S, Drakeley CJ, Kachur SP, Killeen GF. Increased proportions of outdoor feeding among residual malaria vector populations following increased use of insecticide-treated 
nets in rural Tanzania. Malar J. 2011;10:80.

37. Lindblade KA, Gimnig JE, Kamau L, Hawley WA, Odhiambo F, Olang G, et al. Impact of sustained use of insecticide-treated bednets on malaria vector species distribution and culicine mosquitoes. J Med Entomol. 2014;43:428-32.

38. Nkya TE, Akhouayri I, Poupardin R, Batengana B, Mosha F, Magesa S, et al. Insecticide resistance mechanisms associated with different environments in the malaria vector Anopheles gambiae: a case study in Tanzania. Malar J. 2014;13:28.

39. Reid MC, McKenzie FE. The contribution of agricultural insecticide use to increasing insecticide resistance in African malaria vectors. Malar J. 2016;15:107.

40. Ranson H, Lissenden N. Insecticide resistance in African Anopheles mosquitoes: a worsening situation that needs urgent action to maintain malaria control. Trends Parasitol. Elsevier; 2016;32:187-96.

41. Djègbè I, Boussari $O$, Sidick $A$, Martin $T$, Ranson $H$, Chandre $F$, et al. Dynamics of insecticide resistance in malaria vectors in Benin: first evidence of the presence of L1014S kdr mutation in Anopheles gambiae from West Africa. Malar J. 2011;10:261.

42. Coetzee M, Koekemoer LL. Molecular systematics and insecticide resistance in the major African malaria vector Anopheles funestus. Annu Rev Entomol. 2013;58:393-412.

43. Brooke BD, Kloke G, Hunt RH, Koekemoer LL, Tem EA, Taylor ME, et al. Bioassay and biochemical analyses of insecticide resistance in southern African Anopheles funestus (Diptera: Culicidae). Bull Entomol Res. 2001;91:265-72.

44. Organization WH. Global report on insecticide resistance in malaria vectors: 2010-2016. World Health Organization; 2018;

45. Edi CVA, Koudou BG, Jones CM, Weetman D, Ranson H. Multiple-insecticide resistance in Anopheles gambiae mosquitoes, Southern Cote d'Ivoire. Emerg Infect Dis. 2012;18:1508.

46. Corbel V, N'Guessan R. Distribution, mechanisms, impact and management of insecticide resistance in malaria vectors: a pragmatic review. Anopheles mosquitoes-New insights into Malar vectors. IntechOpen; 2013.

47. Awolola TS, Oduola OA, Strode C, Koekemoer LL, Brooke B, Ranson H. Evidence of multiple pyrethroid resistance mechanisms in the malaria vector Anopheles gambiae sensu stricto from Nigeria. Trans R Soc Trop Med Hyg. 2009;103:1139-45.

48. Ranson H, N'Guessan R, Lines J, Moiroux N, Nkuni Z, Corbel V. Pyrethroid resistance in African anopheline mosquitoes: what are the implications for malaria control? Trends Parasitol. 2011;27:91-8.

49. Hemingway J, Ranson H, Magill A, Kolaczinski J, Fornadel C, Gimnig J, et al. Averting a malaria disaster: will insecticide resistance derail malaria control? Lancet. 2016;387:1785-8.

50. Toé KH, Jones CM, N’Fale S, Ismail HM, Dabiré RK, Ranson H. Increased pyrethroid resistance in malaria vectors and decreased bed net effectiveness, Burkina Faso. Emerg Infect Dis. 2014;20:1691. 
51. Coleman M, Hemingway J, Gleave KA, Wiebe A, Gething PW, Moyes CL. Developing global maps of insecticide resistance risk to improve vector control. Malar J. 2017;16:86.

52. Gleave K, Lissenden N, Richardson M, Choi L, Ranson H. Piperonyl butoxide (PBO) combined with pyrethroids in insecticide-treated nets to prevent malaria in Africa. Cochrane Database Syst Rev. 2018;

53. Protopopoff N, Mosha JF, Lukole E, Charlwood JD, Wright A, Mwalimu CD, et al. Effectiveness of a long-lasting piperonyl butoxide-treated insecticidal net and indoor residual spray interventions, separately and together, against malaria transmitted by pyrethroid-resistant mosquitoes: a cluster, randomised controlled, two-by-two fact. Lancet. 2018;391:1577-88.

54. Smith DL, Dushoff J, Snow RW, Hay SI. The entomological inoculation rate and Plasmodium falciparum infection in African children. Nature. 2005;438:492.

55. Beier JC, Killeen GF, Githure JI. Entomologic inoculation rates and Plasmodium falciparum malaria prevalence in Africa. Am J Trop Med Hyg. 1999;61:109-13.

56. Leake CJ. Mosquito ecology field sampling methods:. MW Service. Barking, Essex, UK: Elsevier Science Publishers, 1993. xiii+ 988 pp. Pricef 95. ISBN 1-85166-798-9. Trans R Soc Trop Med Hyg. 1994;88:606.

57. Tusting LS, Thwing J, Sinclair D, Fillinger U, Gimnig J, Bonner KE, et al. Mosquito larval source management for controlling malaria. Cochrane Database Syst Rev. John Wiley \& Sons, Ltd; 2013;

58. Geissbühler Y, Kannady K, Chaki PP, Emidi B, Govella NJ, Mayagaya V, et al. Microbial larvicide application by a large-scale, community-based program reduces malaria infection prevalence in urban Dar es Salaam, Tanzania. PLoS One. Public Library of Science San Francisco, USA; 2009;4:e5107.

59. Choi L, Majambere S, Wilson AL. Larviciding to prevent malaria transmission. Cochrane Database Syst Rev. John Wiley \& Sons, Ltd; 2019;

\section{Figures}




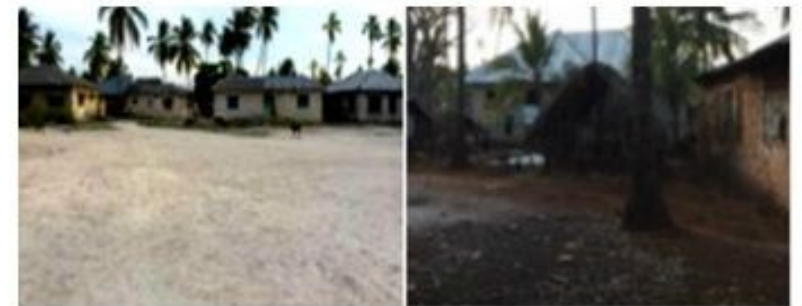

Bwejuu

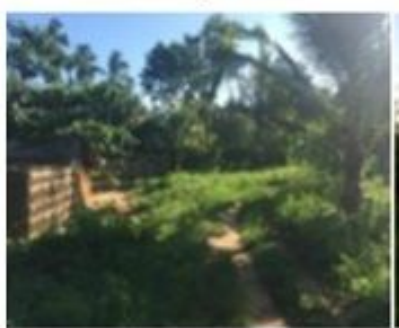

Miwani

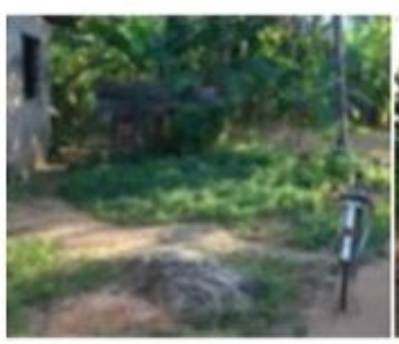

Tunduni
Charawe

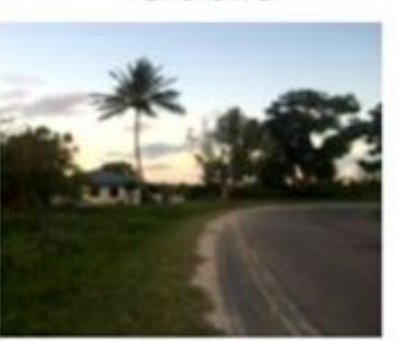

Mbaleni

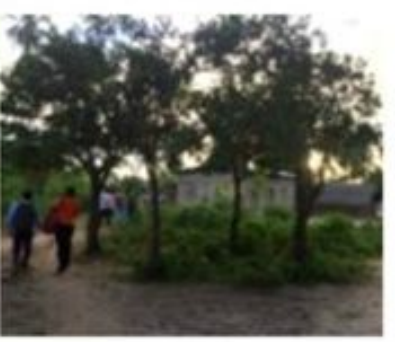

Donge Mchangani
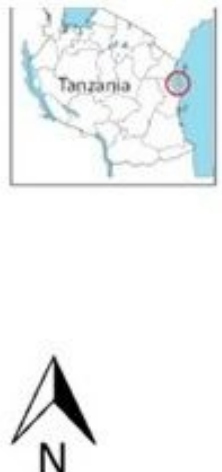

Study sites

Bwejuu

Charawe

Donge Mchangani

Mbaleni

Miwan

Tunduni

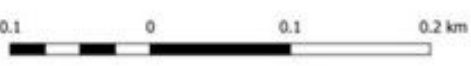

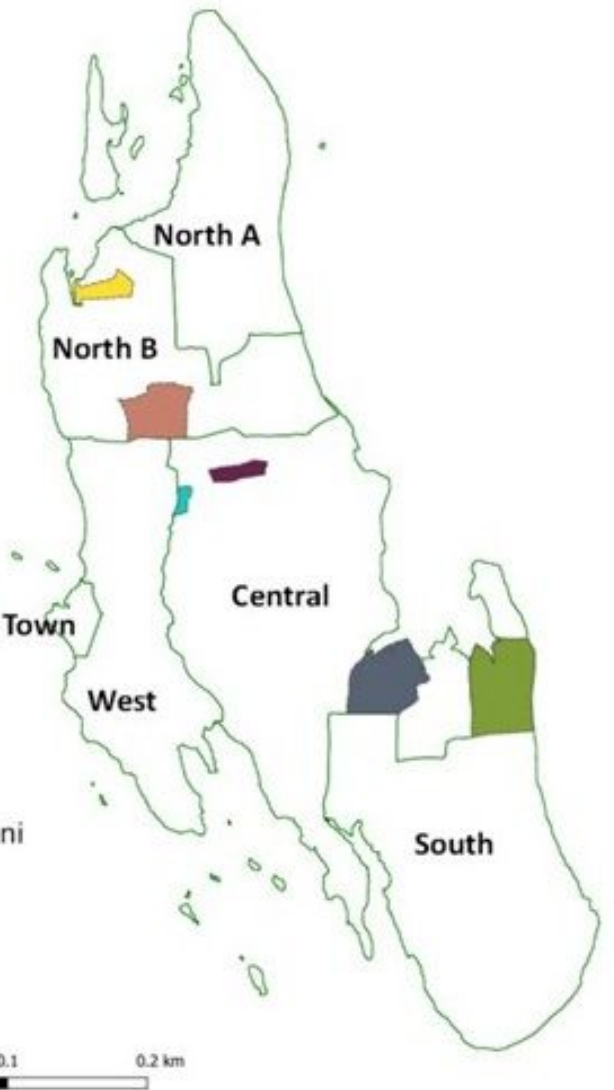

\section{Figure 1}

The figure presents the six study sites in Unguja and a snapshot of their characteristics. 


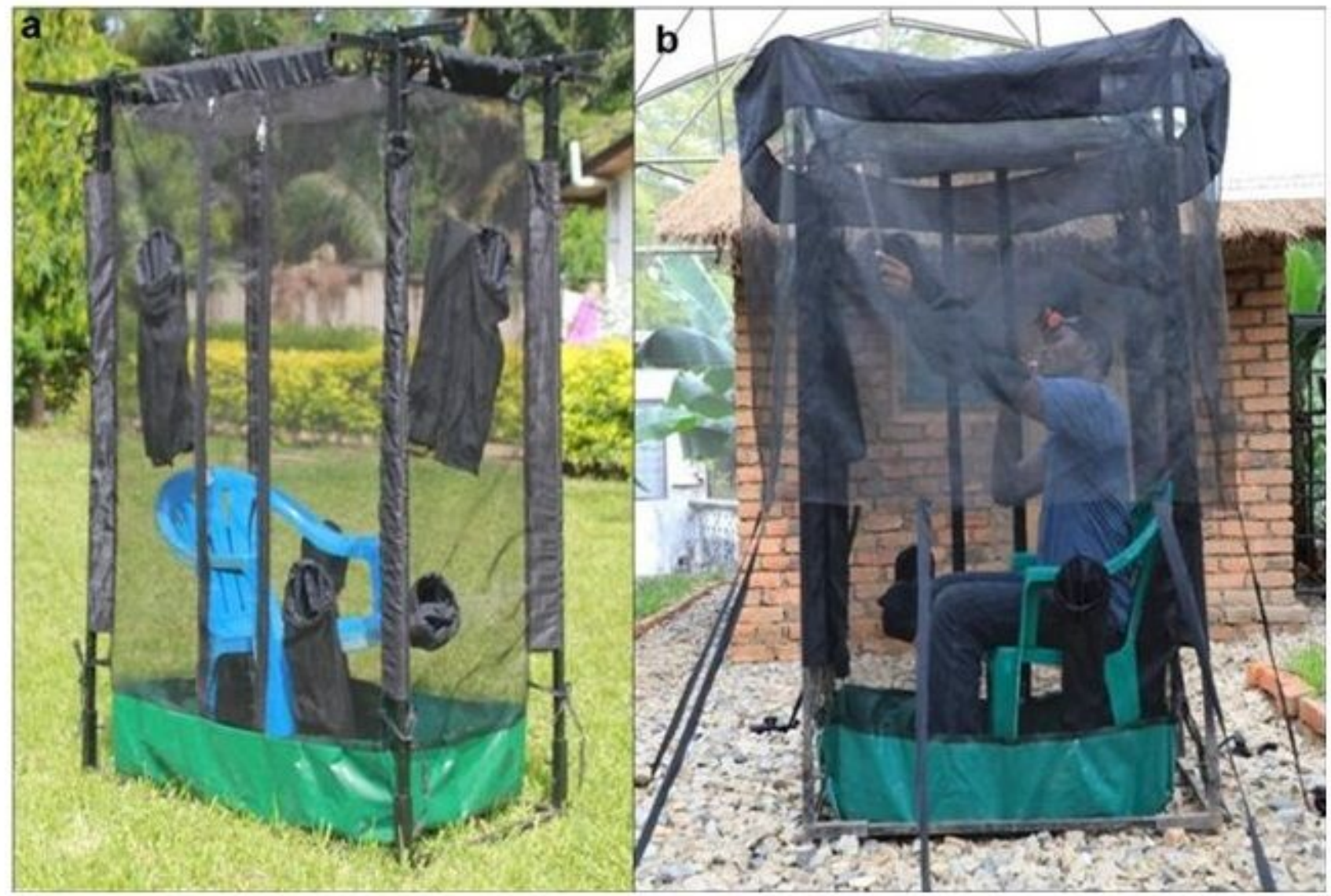

\section{Figure 2}

Miniaturized Double Net Trap (DN-Mini). Panel A provides a clear picture of DN-Mini trap and panel B show a volunteer collecting mosquito while seating down but not freely exposed to mosquitoes. 


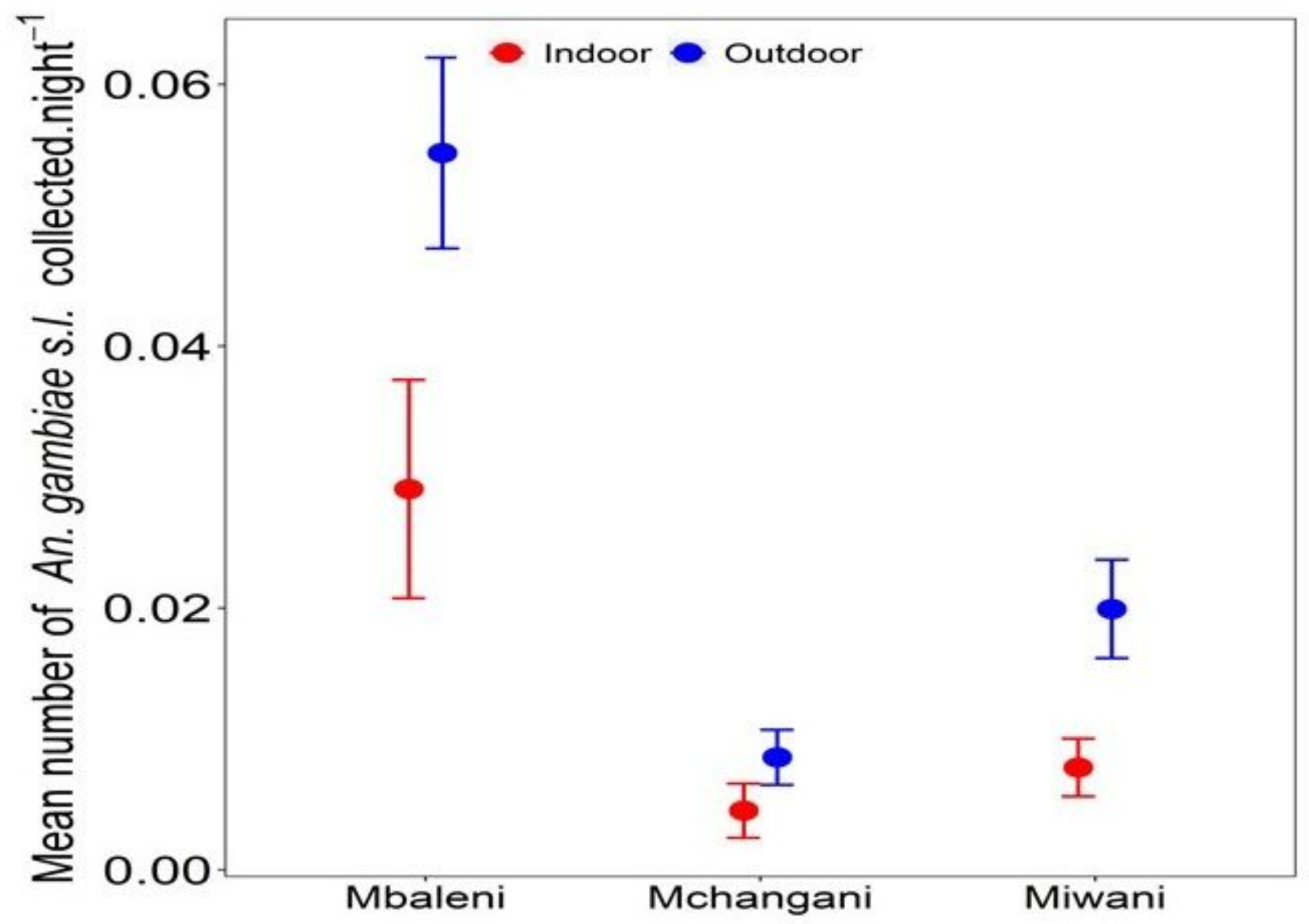

Figure 3

Mean number of An. gambiae s.l. collected indoor and outdoor per night in Mbaleni, Donge Mchangani and Miwani. 

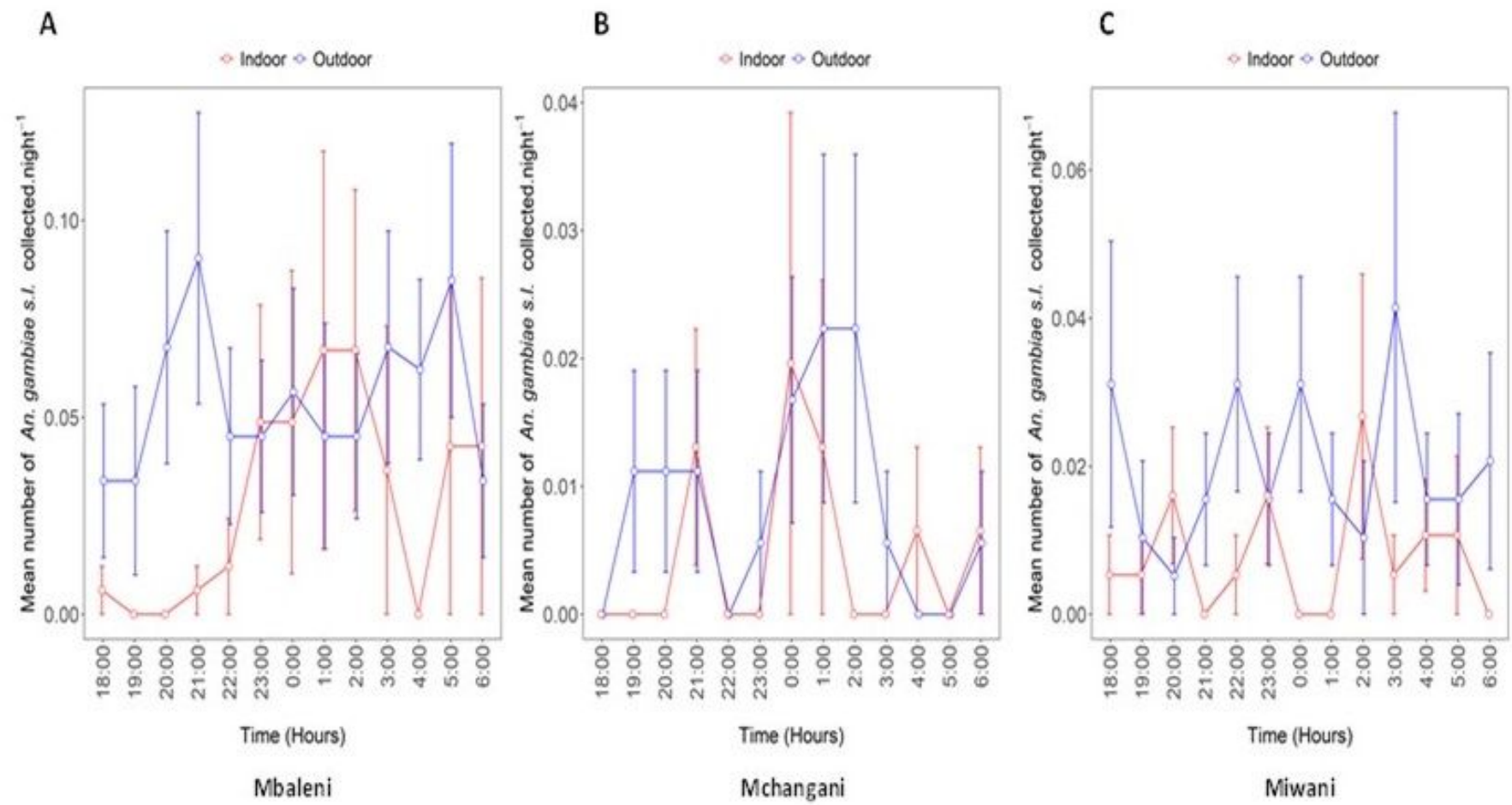

\section{Figure 4}

Hourly mean number of An. gambiae s.I caught by DN-Mini in Mbaleni (A), Donge (B), and Miwani (C). 


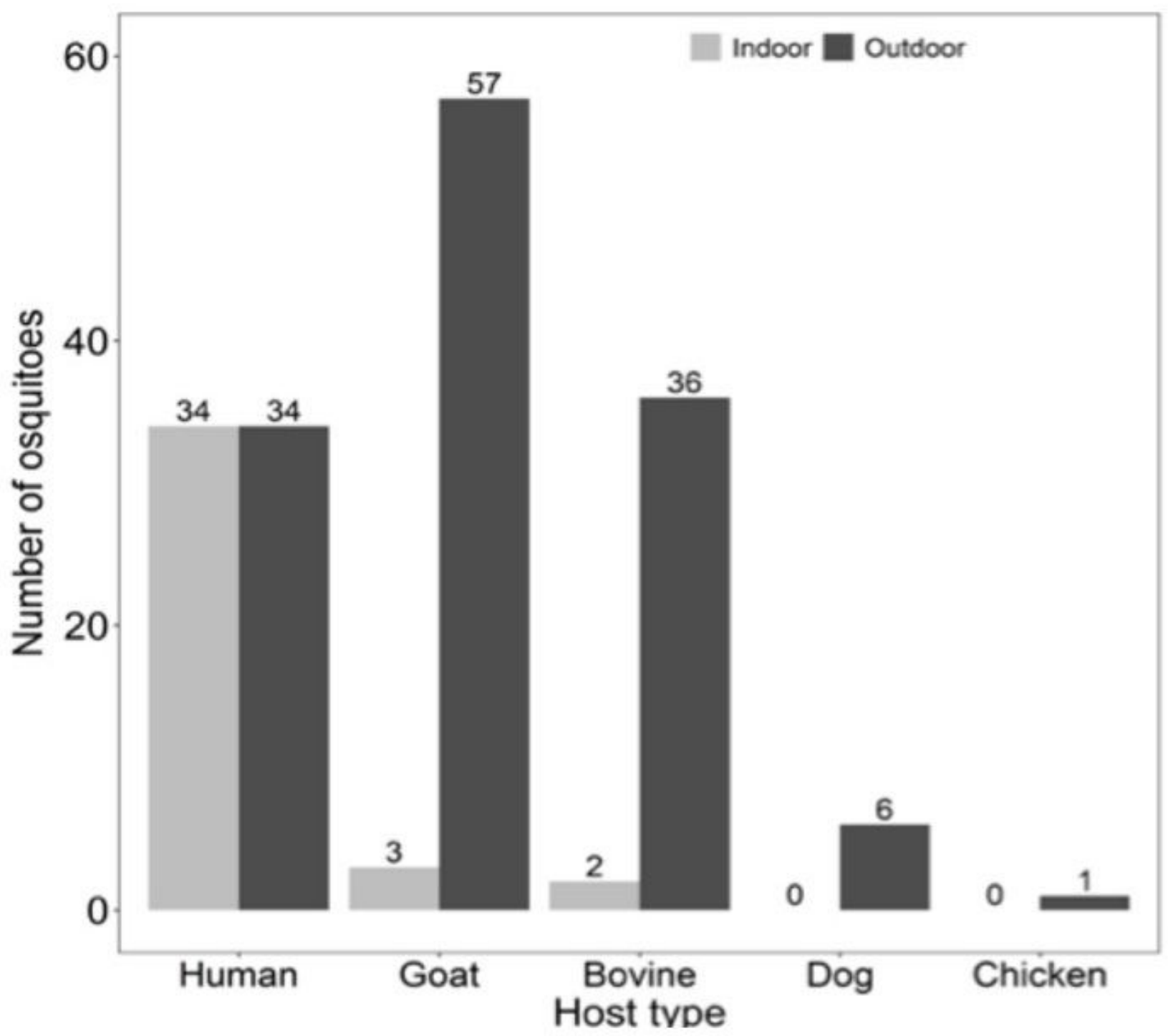

Figure 5

Showing blood meal host preferences displayed by An. gambiae s.I. caught by MD-Min both outdoor and indoor dwellings. 